\title{
GIANT CELL TUMOR IN THE PROXIMAL PHALANX WITH PULMONARY METASTASIS: CASE REPORT AND LITERATURE REVIEW
}

Frederico Carvalho de Medeiros ${ }^{1}$, Fernando Carvalho de Medeiros², Izabella de Campos Carvalho Lopes ${ }^{3}$, Guilherme Carvalho de Medeiros ${ }^{4}$, Eduardo Carvalho de Medeiros ${ }^{5}$

\section{ABSTRACT}

This is a case report on a giant cell tumor (GCT) in the proximal phalanx of the third finger of the left hand, with pulmonary metastasis. The patient presented pain in the finger without any previous history of trauma. Clinical examination, radiographic imaging and magnetic resonance imaging were carried out. A histological evaluation was carried out from an incisional biopsy, taking the hypothesis of GCT. The patient underwent amputation of the finger and the diagnosis was confirmed by means of microscopy on the specimen. The patient was followed up because of the risk of lung metastasis, which was shown by radiographic examination and computed tomography on the chest, and thoracotomy was performed. Since then, there has been an improvement in the symptoms that had been reported preoperatively, and no local recurrence or new metastasis has been found.

Keywords - Giant cell tumors/surgery; Finger Phalanges; Amputation; Neoplasm Metastasis

\section{INTRODUCTION}

Giant cell tumor (GCT) is a benign neoplasia in the majority of cases, and accounts for around 5\% of primary bone tumors. It is generally located in the epiphysis and metaphysis of the long bones. In a large number of cases, it extends close to the articular cortex, and its occurrence in the bones of the hand is rare. GCT occurs more frequently in the third and fourth decades of life, with a slight prevalence in women ${ }^{(1)}$.

Clinically, its behavior is locally aggressive ${ }^{(1)}$ and the main complaint is pain, followed by increased limb size and functional impairment ${ }^{(2)}$. In rare cases, pulmonary metastasis occurs ${ }^{(1)}$.

The diagnosis is established through clinical correla- tion, imaging exams and histopathological data to rule out other lesions with a similar histological pattern ${ }^{(1)}$.

The treatment is surgical with a recurrence rate of around $5 \%$ to $10 \%{ }^{(1)}$.

The objective of this work is to report on a case of GCT in the proximal phalanx of the third finger of the left hand, which evolved to pulmonary metastasis.

\section{CASE REPORT}

Female patient, aged 25 years, with a history of pain in the proximal phalanx of the third finger of the left hand, lasting for about one month. She reported an increase in local volume, paresis and limited movements (flexion and extension) of the finger. She reported no trauma or comorbidities. She was

\footnotetext{
1 - Neurology Resident at the Hospital Santa Casa de Misericórdia de Belo Horizonte - Minas Gerais.

2 - Nephrology Resident at the Hospital Vera Cruz de Belo Horizonte - Minas Gerais.

3 - Student in the Fifth Year of Medicine of the Faculdade de Ciências Médicas de Minas Gerais.

4 - General Surgeon of the Instituto Mário Penna - Hospital Luxemburgo de Belo Horizonte - Minas Gerais.

5 - Surgery Resident at the Hospital LifeCenter and Hospital Vera Cruz de Belo Horizonte - Minas Gerais.
} 
not taking any regular medication. On examination, there was pain on palpation in the proximal phalanx and metacarpophalangeal joint, and limited flexion and extension of the third finger.

The x-ray performed in May 2007 showed hypertransparency with increased bone volume (Figure 1).

After one month, the lesion showed significant growth (Figure 2).

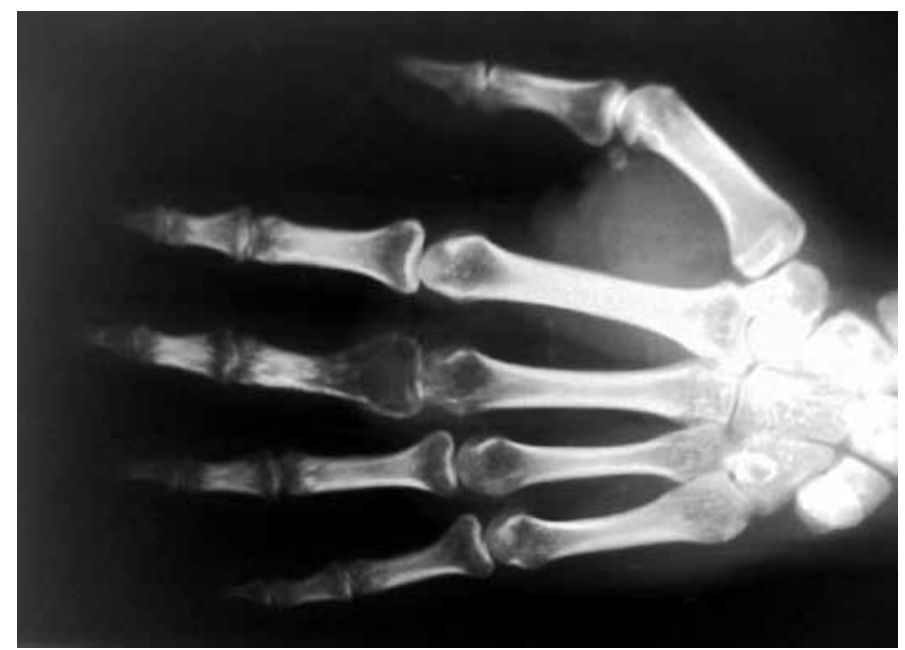

Figure 1 - Hypertransparency in the proximal phalanx of the third finger.

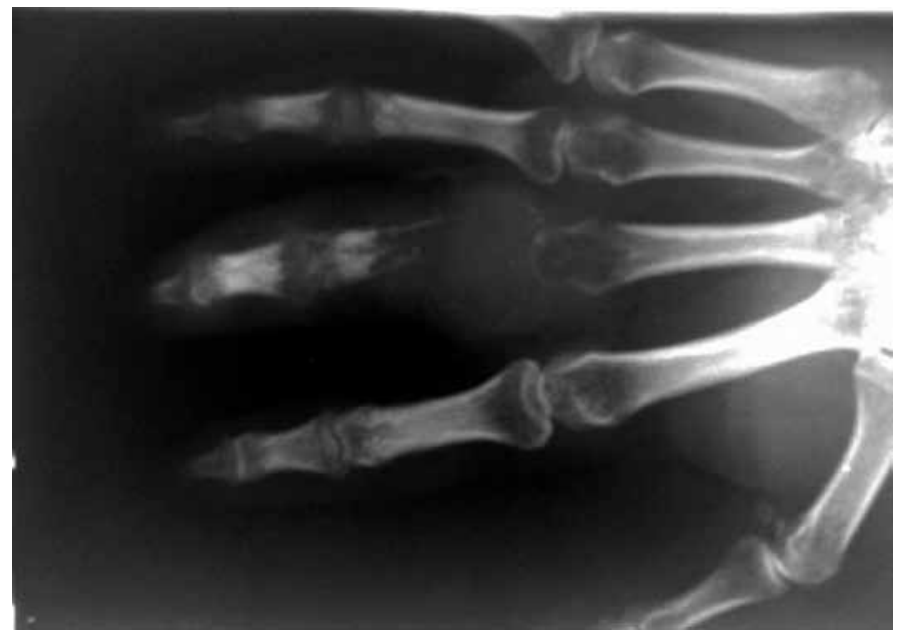

Figure 2 - Evolution of the lesion in one month.

In July 2007, incisional biopsy was performed, with histological findings suggestive of GCT of the bone, extending to the pariphalangeal soft tissues: histological sections of mesenchymal lesion consisting of proliferation of osteoclast-type giant cells, uniformly distributed with the mononucleated cells lacking atypia, with the presence of mitotic activity. In the same month, nuclear magnetic resonance imaging (MRI) showed a large expansive lesion in the two proximal thirds of the phalanx of the third finger of the left hand, with destructive appearance and clear margins, measuring at its widest points: 27.0 $\mathrm{x} 24.0$ x $24.0 \mathrm{~mm}$. Characterized by hyposignal in $\mathrm{T} 1$ and hypersignal in $\mathrm{T} 2$, containing areas with cystic appearance in the center. The adjacent extensor tendons and other bone and joint structures were preserved. At the end of July 2007, the patient was submitted to amputation of the third finger, transposing the index finger to the resection site (Figure 3).

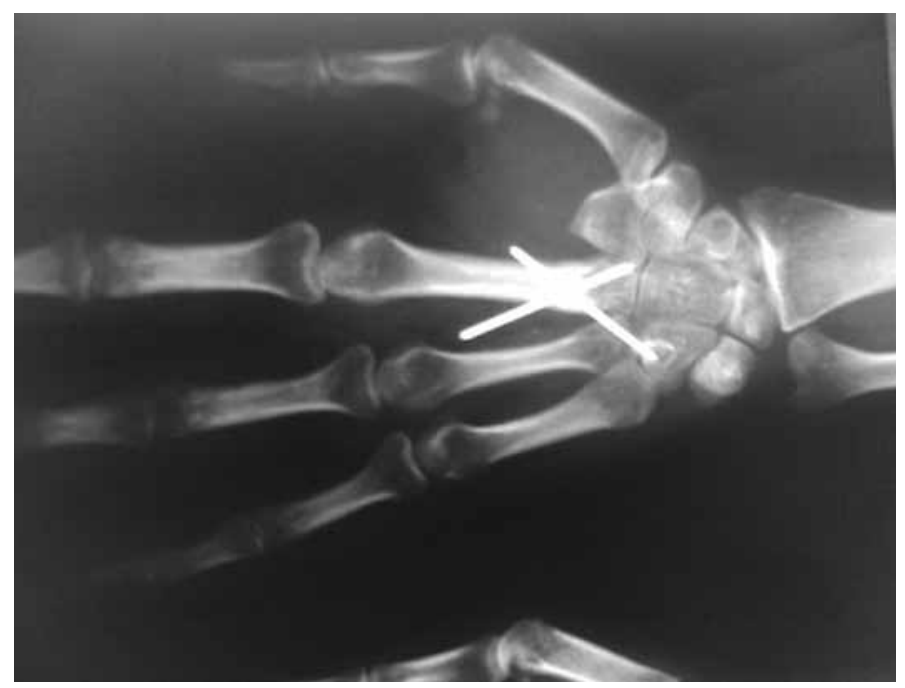

Figure 3 - Amputation of the third finger, transposing the index finger to the resection site.

The piece was sent for anatomapathological study, which confirmed the diagnosis of GCT. Macroscopic examination of the surgical piece revealed a whitish, elastic tumoration with extensive areas of hemorrhage, measuring $2.0 \mathrm{~cm}$ at its widest diameter to $5.0 \mathrm{~cm}$ from the proximal margin of the sample. The lesion presented impairment of the proximal phalanx, with destruction of the cortex and bone marrow, and invasion to the surrounding soft tissues. Microscopically, characteristics of incisional biopsy were apparent, with the presence of angiolymphatic tumor invasion, but without evidence of malignant sarcomatous transformation. Surgical margins free (Figure 4).

In August 2007, the patient underwent full-body bone scintigraphy revealing hyperemia and inflammation of the soft tissues of the left hand, compatible with non-specific post-surgical alterations, secondary to exeresis of the GCT. The scintigraphic pattern was not compatible with additional lesions of the under- 


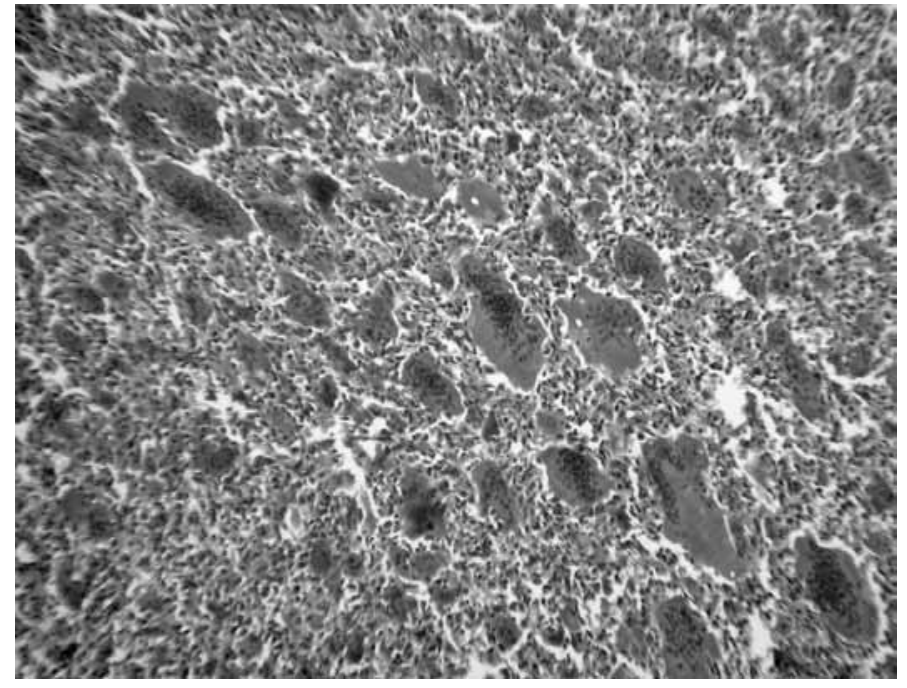

Figure 4 - Microscopy of the giant cell tumor affecting the proximal phalanx.

lying pathology in the other skeletal segments (absence of multicentric GCT).

In the postoperative evolution, the patient continued to have free movements in the left hand, without complaints, and showed improvement with physiotherapy. During postoperative follow-up, a semestral radiological study was carried out which, 11 months after excision of the lesion, showed nodular formations in both lungs, one in the right middle/upper third (around $5.0 \mathrm{~mm}$ ) and the other in the left lower third (around $14.0 \mathrm{~mm}$ ). Multislice computed tomography of the thorax was performed, showing three nodular images in pulmonary parenchyma with density of the soft tissues, one located in the anterior segment of the right upper lobe $(6.0 \mathrm{~mm})$ and two located in the posterior basal segment of the left lower lobe (15.0 and $4.0 \mathrm{~mm}$ ) (Figure 5).

In July 2008, the patient was submitted to exploratory thoracotomy of the left lung, and in the following month, the same procedure was carried out in the right lung. Exeresis was performed of the four nodules on the left and six nodules on the right, all benign pulmonary metastasic GCT, without high degree transformation, as confirmed in the anatomopathological tests (Figure 6). The patient evolved well, without complaints, and is in tomographic control without evidence of local recurrence or metastasis in the lungs. She has resumed her normal activities and continues in follow-up: every three months in the first year, every six months up to five years after the treatment, and then annually after this period.

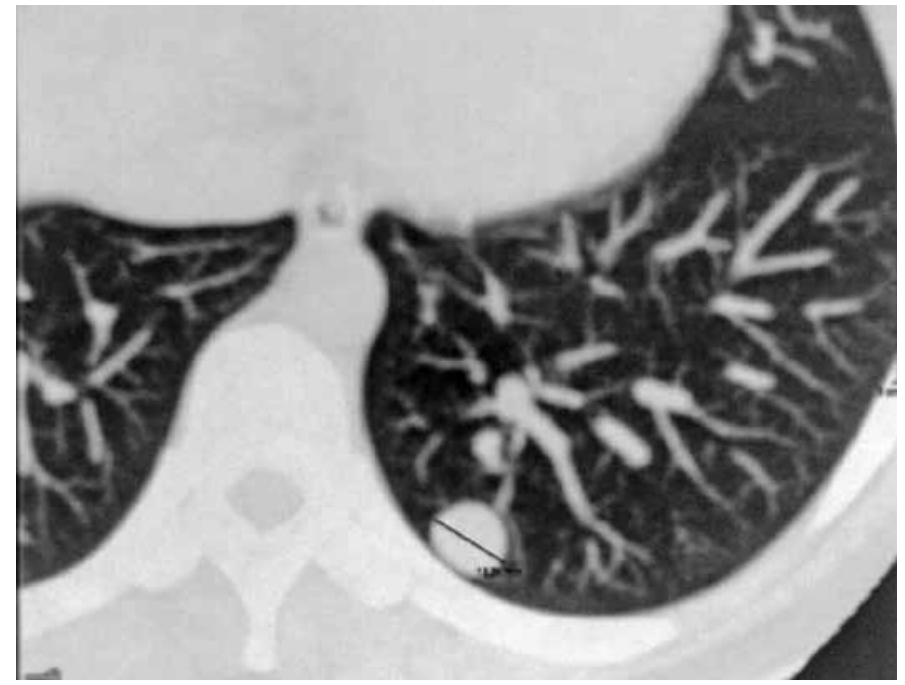

Figure 5 - Multislice computed tomography of the thorax with metastasis in the left lung.

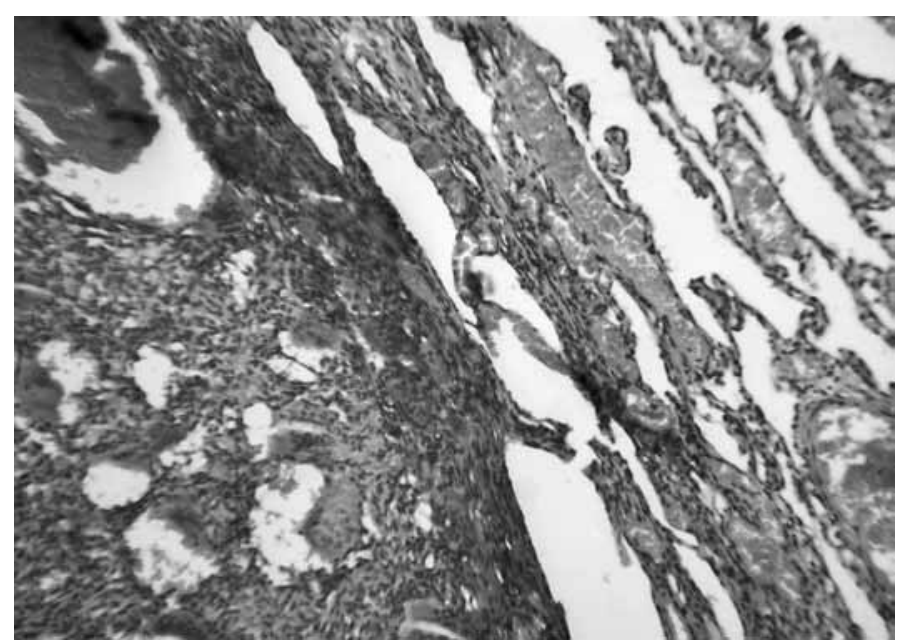

Figure 6 - Pulmonary metastasis of intraparenchymal giant cell tumor of the bone.

\section{DISCUSSION}

GCT of the bone is a benign neoplasia, locally aggressive, with uncertain biological behavior ${ }^{(1,3,4)}$. Approximately $5 \%$ to $10 \%$ of patients present malignant evolution ${ }^{(1)}$.

GCT represents $5 \%$ to $8 \%$ of all primary bone tumors, and $20 \%$ of all benign bone tumors ${ }^{(1,3-7)}$. Some studies show a slight prevalence in women compared to men (ratio of $1.3: 1)^{(1,4,5)}$, and a prevalence in the third and fourth decades of life ${ }^{(3,7,8)}$. The lesion is rarely found before fusion of the epiphyseal plate ${ }^{(3,7)}$.

\section{Location}

Its usual location is in the epiphysis of the long bones in isolated form; the distal end of the femur and proximal end of the tibia correspond to $45-55 \%$ of the 
cases. Other locations include: the distal portion of the radius (10-12\%), sacrum (4-9\%), proximal humerus (4-8\%), proximal femur (4\%) and less frequently in the vertebral bodies $(2.5 \%)$ and bones of the hands and feet ${ }^{(1,7)}$.

The condition is rare in the bones of the hand $(2-4 \%)^{(2,3,7,9,10)}$. Out of 1547 cases of GCT of the bone collected in various studies, only 70 were located in the hands or feet ${ }^{(11)}$. It affects patients 10 years younger than the average age (32 years) for GCT occurring in other locations ${ }^{(11)}$, with more aggressive behavior $^{(9)}$ and earlier recurrence ${ }^{(2)}$. The most common locations are the metaphyseal region of the metacarpals and phalanges. The tumor grows in the direction of the diaphysis, which complicates the treatment ${ }^{(10)}$.

\section{Clinical aspects}

The majority of patients with GCT are oligosymptomatic with localized pain, with insidious onset and progressive deterioration $^{(1,4)}$. The disease evolves with increased volume and functional incapacity of the limb, particularly if the lesion is near the joint ${ }^{(2,3)}$. However, there may be acute pain as a result of pathological fracture $^{(3,7,9)}$. In some cases, the tumor grows quickly, with thinning and rupture of the bone cortex and invasion of the adjacent soft tissues, but without invading and ulcerating the skin and subcutaneous cell tissue ${ }^{(10,11)}$. In the hand, the clinical aspect has peculiar characteristics. Pain and swelling occur sooner than in GCT in other locations, due to the fact that the tumor is close to the surface, and the high mobility of the fingers ${ }^{(11)}$.

\section{Image}

The classical radiographic aspects of GCT of the bone define it as an eccentric, swollen, lytic epiphyseal-metaphyseal lesion, not always with clearly-defined margin ${ }^{(3,4,7,9)}$. Its appearance is radiotransparent, with thinning of the cortical bone and absence of internal calcifications, marginal sclerosis, or periosteal reaction. However, there is no pathognomonic characteristic $^{(9)}$. Although computed tomography $(\mathrm{CT})$ is of little use in the differential diagnosis, it confirms the absence of calcified matrix, shows the margins of the lesion, and reveals the extent of subcortical bone loss prior to surgical reconstruction ${ }^{(1)}$. MRI is also used in the preoperative evaluation ${ }^{(1)}$. This is considered the best method for delineating intraosseous, extraosseous and intra-articular tumors ${ }^{(1,7)}$. Its greatest utility is for demonstrating recurrence of the tumor ${ }^{(1)}$.
In relation to skeletal screening by bone scintigraphy, GCT presents local hypercaptation due to the increased reactive osteoblastic activity, with broad concentration of the radioindicator in the lesion. In up to $57 \%$ of the cases, the "donut sign" of central photopenia is present. The exam should be carried out to search for other bone lesions ${ }^{(12,13)}$.

The radiological classification of GCT of the bone was described by Enneking, and subsequently by Campanacci. There are three stages that correlate the local tumor according to its aggressiveness and risk of local recurrence $^{(7,8)}$. Stage 1 is the less common. The tumor is small and the cortical layer is preserved. There is no extension to the joint cartilage. Symptoms are absent or minimal. Stage 2 corresponds to $75 \%$ of the GCT in its initial presentation. The tumor has extended to the cortex, which is deformed by the expansion of the tumor. There is no extension to the adjacent soft tissues. Stage 3 is characterized by extreme aggressiveness; the tumor is large in volume, destroying the bone and invading the surrounding tissues ${ }^{(7,8)}$; as presented in the case reported here. The highest rate of recurrence is observed in tumors that are in this phase ${ }^{(7,8)}$.

\section{Histomorphological aspects}

In its morphological aspect, GCT of the bone is solid, large, brown in color, with yellow areas of necrosis and dark red areas of hemorrhage. In cases with slower evolution, there are areas of whitish, starshaped fibrosis, with firm consistency at the core ${ }^{(14)}$. Histologically, the neoplasic tissue is highly vascularized, consisting of stroma with oval or fusiform cells, and numerous multinucleated giant cells, the nuclei of which are identical to those of the stroma cell ${ }^{(14)}$. There is little or no intercellular substrate, except for some collagen fibers. Mitotic figures may be numerous, but without abnormalities $^{(7)}$.

\section{Differential diagnosis}

Differential diagnosis should be performed with tumors that contain giant cells, like aneurismal bone cyst, giant cell reparative granuloma and brown tumor of hyperparathyroidism. These pathologies present a similar radiological pattern. Through the histological findings, differentiation is possible, except with brown tumor of hypoparathyroidism, which requires biochemical studies for its diagnostic definition ${ }^{(7,8,11)}$. Metastatic disease and multiple myeloma can also be included ${ }^{(3)}$. 


\section{TREATMENT}

The treatment of GCT is surgical ${ }^{(1,4,5,10)}$. The conduct should be well-planned and individualized, due to the unpredictable nature of the neoplasia in terms of its local prognosis ${ }^{(4)}$. The greatest challenge is due to the aggressive local behavior of the tumor and its tendency to recur ${ }^{(6,8)}$. Compared with GCT in proximal locations, tumors of the hand are presented in advanced stages with greater bone destruction and extension for diaphysis, which complicates the treatment. The objective of the treatment in the hands is to achieve local control of the tumor and avoid recurrences, preserve the functions of the hand, and maintain a good esthetic standard ${ }^{(3,10)}$. The types of treatment described in the literature are: curettage, curettage with bone graft, radiotherapy, amputation and resection with reconstruction ${ }^{(5)}$. Curettage, whether in isolation or associated with bone graft, is the most common form of treatment, but it presents a rate of recurrence of around $90 \%{ }^{(2,8)}$. Curettage is not, therefore, the ideal intervention. Radiotherapy should also not be used as the primary procedure as it is associated with malignant transformation. Amputation, although it reduces the recurrence rates, is esthetically disfiguring and causes loss of functionality of the limb ${ }^{(2,5)}$. In the present case, this procedure was carried out in order to prevent recurrence, due to the clinical condition presented. Resection with reconstruction of the articulation of the proximal phalanx with the metacarpus can be carried out with a bone graft, prosthesis or with polymethylacrilate, which re-establishes the structural and functional integrity of the metacarpophalangeal joint ${ }^{(2,5)}$. These last two forms of treatment are considered the treatments of choice in stage 3 lesions of the hand, where there is invasion of the surrounding soft tissues ${ }^{(8)}$.

\section{Prognosis}

The rate of recurrence with the appropriate surgical technique is approximately $5 \%$ to $10 \%{ }^{(1,7)}$ and the majority occur around 12 to 18 months after the therapy ${ }^{(7)}$. There is a study that reports a peak of recurrence three years after surgery ${ }^{(1)}$. In the hands, the recurrence rate is higher ${ }^{(8,11)}$, approximately $70 \%{ }^{(11)}$. A literature review indicates that patients with recurrence should be carefully monitored due to the higher malignant potential of the recurrent disease, and the higher propensity to metastasis ${ }^{(3)}$. Thus, due to the small, but definite risk of pulmonary metastasis, clinical follow-up and imaging exams are necessary for the rest of the patient's life $\mathrm{e}^{(15)}$.

\section{Pulmonary metastasis}

The development of pulmonary metastasis is rare, its incidence varying between studies from $2 \%$ to $6 \%{ }^{(7,16)}$. In the series of Bertoni et al ${ }^{(15)}$ involving 327 cases of GCT of the bone, only six presented pulmonary metastasis. They generally occur in the first years after discovery of the primary bone tumor, at around 3.5 years, on average ${ }^{(16)}$. In relation to the surgical procedure, the appearance of pulmonary metastasis presented an interval of 17 to 40 months, according to a study by Athanasian et al ${ }^{(17)}$, and 16.4 months in the series of Bertoni et $\mathrm{al}^{(15)}$. The progression is generally slow ${ }^{(7)}$. The increased incidence of pulmonary metastasis is associated with the location of the primary tumor in the distal radius, sacrum and hands, stage 3 lesions, aggressive local behavior, and multiple recurrences, characteristics of the tumor ${ }^{(3,7,10)}$. The clinical presentation (age, sex and tumor location) of GCT with pulmonary metastasis is similar to that of GCT without metastasis ${ }^{(15)}$. The majority of pulmonary lesions are asymptomatic, and are incidentally detected during follow-up of the tumor. However, some patients present pulmonary symptoms before the discovery of the primary tumor ${ }^{(16)}$. Regular chest $\mathrm{x}$-ray and CT are therefore recommended ${ }^{(16)}$. The histomorphological findings of the pulmonary metastatic nodules present the same benign morphology as the primary tumor in terms of cellularity, abundance of osteoid, anaplasia and mitotic aspects ${ }^{(7,16,18)}$.

In the search for metastasis, the x-ray shows nodules of homogenous opacity, occasionally with peripheral calcification. Most of the nodules occur in the basal and peripheral regions of the lungs. CT is the most sensitive method and can help determine more accurately the number of lesions and whether there is mediastinal involvement. It is extremely important in the surgical planning for removal of the metastases ${ }^{(16)}$.

In cases of pulmonary metastasis, some tumors regress spontaneously, while others require surgical treatment. Resection of the pulmonary implants, whether by metastectomy, general resection or lobectomy, not only prevents extension of the lesion with progressive pulmonary dysfunction and confirms the diagnosis, but it may be a determining factor for the cure, without the need for additional treatment ${ }^{(15,16,18)}$. Lesions that 
are inaccessible to surgical treatment, rapidly recurring lesions, lesions with incomplete resection, or multiple lesions may respond to chemotherapy, including Interferon. High doses of Cisplatin, Cyclophosphamide, Methotrexate and Doxorubicin can prolong the diseasefree time. The response is variable. Many patients die from the side effects of chemotherapy, such as secondary sepsis due to agranulocytosis ${ }^{(7,15,16)}$. Interferon alpha-2 is a therapeutic option due to its antiangiogenic action, which results in a major reduction in tumor size ${ }^{(4)}$. Radiotherapy may also be used in these situations, despite the risks of malignant sarcomatous transformation ${ }^{(15,16)}$. This possibility of sending metastases is still a source of confusion for many authors, who start to consider GCT and treat it like a high malignity neoplasm. Commonly, descriptions of chemotherapy and even radiotherapy treatment are seen, in cases considered as malignization of a GCT. Benign histological analysis of the pulmonary nodule corroborates the affirmation that there is no malignant transformation of the $\mathrm{GCT}^{(19)}$, therefore, these two last therapies are little used, as a series of studies describes that the absence of treatment of the pulmonary metastasis from the GCT of bone does not reduce long-term survival ${ }^{(15,16,18)}$.

\section{Follow-up}

Due to the high incidence of local recurrence and the risk of pulmonary metastasis, it is extremely important to closely monitor these patients ${ }^{(7)}$.

Follow-up after treatment should initially be done every three to four months and should include physical and x-ray tests on the affected bone. This will enable any recurrence to be detected at an early stage. CT or MRI are useful for clarifying a suspected recurrence. After two to three years, the follow-up should be every six months, and then annually after five years of treatment. Chest x-ray should be requested in each follow-up visit due to the risk of pulmonary metastasis. Chest CT can be performed on diagnosis to check for early signs of pulmonary metastasis since CT is more sensitive than X-ray. Subsequently, in the absence of lesions, the patient is followed-up with $\mathrm{X}$-ray at the above-mentioned intervals ${ }^{(7)}$.

\section{CONCLUSION}

GCT in the hand is a rare, benign, but locally aggressive entity. It evolves earlier than GCT in other locations. It is oligosymptomatic, with prevalence of pain and increased volume. It mainly affects young women, who are more subject to pulmonary metastasis. The diagnosis is based on the clinical, radiological and histopathological aspects. The treatment is surgical, but there is no consensus in the literature. Cases should be assessed individually to ensure safe intervention, seeking to prevent recurrences and functional limitations.

\section{REFERENCES}

1. Gruenwald N, Demos TC, Lomasney LM, Rapp T. The case. Giant-cell tumor Orthopedics. 2006;29(2):167-71.

2. Gadegone WM, Salphale YS, Sonwalker HA, Nagtode PP, Navghare SM. Giant cell tumor of proximal phalanx of ring finger in immature skeleton - Resection and reconstruction by iliac crest graft - A case report. J Orthopaedics [Internet Journal]. 2007 [quoted on 05/25/2009]; 4(2): [about 3p.] Available at: http://www. jortho.org/2007/4/2/e5.

3. Slesarenko YA, Sampson SP, Gould ES. Giant cell tumour of the distal phalanx of the hand. Hand Surg. 2005;10(2-3): 289-91.

4. Camargo OL, Croci AT, Oliveira CRGCM, Baptista AM, Caiero MT, Giannotti MA. Tumor de células gigantes - evolução histórica do seu diagnóstico e tratamento junto ao Instituto de Ortopedia e Traumatologia da FMUSP. Acta Ortop Bras. 2001;9(4):46-52.

5. Mendenhall WM, Zlotecki RA, Scarborough MT, Gibbs CP, Mendenhall NP. Giant cell tumor of bone. Am J Clin Oncol. 2006;29(1):96-9.

6. Boons HW, Keijser LCM, Schreuder HWB, Pruszezynski M, Lemmens JAM, Veth RPH. Oncologic and functional results after treatment of giant cell tumors of bone. Arch Orthop Trauma Surg. 2002;122(1):17-23

7. Turcotte ER. Giant cell tumor of bone. Orthop Clin North Am. 2006;37(1):35-51.

8. Ropars M, Kaila R, Cannon SR, Briggs TWR. Primary giant cell tumours of the digital bones of the hand. J Hand Surg Eur. 2007;32 (2):160-4.

9. Biscaglia R, Bacchini P, Bertoni F. Giant cell tumor of the bones of the hand and foot. Cancer. 2000;88(9):2022-32.

10. Wittig JC, Simpson BM, Bickles J, Kellar-Graney KL, Malawer MM. Giant cell

Rev Bras Ortop. 2011;46(2):205-10

tumor of the hand: superior results with curettage, cryosurgery, and cementation. J Hand Surg. 2001;26(3):546-55

11. López-Barea F, Rodriguez-Peralto JL, García-Girón J, Guemes-Gordo F. Benign metastasizing giant-cell tumor of the hand: report of a case and review of the literature. Clin Orthop Relat Res. 1992;(274):270-74.

12. Catalan J, Fonte AC, Lusa JR, Oliveira AD, Melo ES, Júnior RO et al. Tumor de células gigantes ósseo: aspectos clínicos e radiográficos de 115 casos. Radiol Bras. 2006;39(2):119-22.

13. Cordeiro SZ, Cordeiro PB, Sousa AM, Lannes DC, Pierro GS. Tumor de células gigantes costal ocupando todo o hemitórax. J Bras Pneumol. 2008;34(3): 185-8.

14. Andrade-Filho JS, Barbosa CSP, Aymoré IL, Lemos C. Sistema ósteo-articular. In: Filho GB. Bogliolo patologia. 7a. ed. Rio de Janeiro: Guanabara; 2006. p. 1014-6.

15. Bertoni F, Present D, Sudanese A, Baldini N, Bacchini P, Campanacci M. Giantcell tumor of bone with pulmonary metastases: six case reports and a review of the literature. Clin Orthop Relat Res. 1988;(237):275-85.

16. Cheng JC, Johnston JO. Giant cell tumor of bone: prognosis and treatment of pulmonary metastases. Clin Orthop Relat Res. 1997;(338):205-14.

17. Athanasian EA, Wold LE, Amadio PC. Giant cell tumors of the bones of the hand. J Hand Surg Am. 1997;22:91-8.

18. Seethalakshmi V, Jambhekar NA. Metastatic giant cell tumor of bone: are there associated factors and best treatment modalities? Clin Orthop Relat Res. [Internet Journal]. 2009 [quoted on 07/14/2009]: [about 7p.] Available at: http://www. springerlink.com/content/q263g3096648m181/.

19. Camargo OP. O estado da arte no diagnóstico e tratamento do tumor de células gigantes. Rev Bras Ortop. 2002;37(10):424-9. 